\title{
Forming Theories of Practices for Software Engineering
}

\author{
Kari Smolander \\ Software Engineering and Information Management \\ Lappeenranta University of Technology \\ Lappeenranta, Finland \\ kari.smolander@lut.fi
}

\author{
Tero Päivärinta \\ Computer and Systems Science \\ Luleå University of Technology \\ Luleå, Sweden \\ tero.paivarinta@1tu.se
}

\begin{abstract}
The paper outlines a model for theorizing about development practices, especially taking into account the intended rationale for, actual realization of, and resulting impacts from using particular practices in varying contexts. This includes discussing of two different modes of thinking through which we can approach software development practices: technical rationality vs. reflection-in-action. By framing development practices taking place in software organizations as "organizational practices", the paper also sketches previous practice research in organizations, which has profoundly informed this work. Finally, the paper compares the SEMAT approach to the outlined model, and suggests a few points of critique and complementary elements to the SEMAT initiative, especially in its capabilities towards theorizing.
\end{abstract}

Index Terms-Software development, theory, development practices, practice theory.

\section{INTRODUCTION}

In IEEE Software, Johnson, Eksted and Jacobson [1] have recently argued for "the General Theory for Software Engineering". Especially, they call for theories which should provide predictive and prescriptive support for software engineering, instead of running costly design processes that are plainly based on trial and error. They mention the issue of choosing software development methods in development projects and organizations as an example of significant questions, which should be tackled by such theory. Especially, Johnson et al. state that "many proposed [...] methods, programming languages and requirements specification languages exist, but very few explicit theories explain why or predict that one method or language would be preferable to another under given conditions." (p. 94).

The first SEMAT Workshop on General Theory of Software Engineering in Stockholm, November 2012, suggested that the "dependent variable" of such General Theory at a very general level would be "Software Engineering Success" [2]. The primary candidates for antecedents to explain how software engineering success could be reached, at an abstract level, were suggested to be "Design Thinking Quality" and "Design Practice Quality". Our work focuses on the latter, i.e., the problem of theorizing about design and development practices. We assume that design and development practice as a whole consists of a set of identifiable development practices enacted in development work. The question is how can we connect such theorizing to the "dependent variable", software engineering success, in a meaningful way to create knowledge that would support research, education and concrete development of practices in software development organizations.

In this paper, we develop our argumentation through the following steps. Firstly, we discuss about two different modes of thinking through which we can "appreciate" development practices: technical rationality vs. reflection-in-action [3][4] and briefly sketch the previously established arguments why efforts of understanding and theorizing about practice should focus on the latter. Secondly, by framing development practices taking place in software organizations (including projects) as "organizational practices", we sketch previous practice research in organizations, which has profoundly informed our work. Thirdly, we outline a model that is needed for theorizing about development practices, especially taking into account the intended rationale for, actual realization of, and resulting impacts from using particular practices. Finally, we compare the SEMAT approach to our model, and suggest a few points of critique and complementary elements to the SEMAT initiative, especially if its goal would be to evolve towards a theorizing effort from its current state of being a plain kernel ontology for describing existing or suggested development practices.

\section{THEORIZING ABOUT PRACTICES}

In the core of our approach is the practice of software development, which is "concerned with creating descriptions of the purposes of the software, of its problem domain, of its structure and behavior, of the computations to be performed, of the interfaces between the software and its environment and its users [...]" [5] p. 34. Software development involves numerous practices including those for analysis, design, implementation and quality management. A practice means a more and less organized and a situated activity that is conducted recurrently by human agents [6] or, as Bourdieu [7] defines, practices are "the recognizable patterned actions in which both individuals and groups engage. They are not a mechanical reaction to rules, 
norms or models, but a strategic, yet regulated improvisation responding to the dialectical relationship between a specific situation in a field and habitus" ([8], p. 204, referring to [7], p. 67 ). This kind of organic view to practices implies that in the software development context practices may include both thoroughly organized use of predefined development methodologies and loosely organized and even emergent activities that may use individual tools or techniques at hand.

\section{A. Technical Rationality vs. Reflection-in-Action}

Already in the 1980's, Mathiassen [9] noted that a methodology is not the same as a practice. A working practice is what is actually done in a situation and it is the concrete actions taken [3]. This kind of viewpoint has its background on Schön's seminal book on the reflective practitioner [10], where Schön makes a distinction between two modes of thinking: technical rationality and reflection-in-action.

In technical rationality knowledge is a result of science and must be separated from practice. Practice then is fundamentally different from research. It includes application of theory, which is produced by research [3]. Technical rationality also supposes that situations are known beforehand: they fall into categories defined by scientific research. The other mode of thinking, reflection-in-action, sees situations as unique, complex, uncertain and value-conflictual. As in modern knowledge management research (e.g. [11][12]), knowledge is inseparable from action. This also implies that practice is not separable from research: theorizing needs contribution from the practice and tasks in practice include also research. Table 1 describes the most significant differences between these two modes of thinking [3].

Research on software engineering methodologies and techniques has traditionally adopted the mode of technical rationality and focused on documenting prescribed procedures, techniques, tools and notations for software development [13], [14]. The purpose of research is then to describe the essential phenomena to practitioners, so that they can take the right theories, tools, and techniques into use to succeed in software development. This seems, at the first sight, also to be the case of SEMAT Essence [15], which defines a prescribed ontology of software development to be used by practitioners. It fulfills the attributes of technical rationality: it defines the categories of reality, it is a result of science separated from practice, and practice is seen as application of SEMAT. However, by adhering to a long research tradition on actual development practices in systems and software development organizations (summarized e.g. in [16]), we believe that practices in a software development organization do not always follow technical rationality. Instead, they are contextual and evolve over time when professionals reflect in action [16]. In the next subsection we will briefly look at how organizational research has approached practices. We think that software engineering theory could benefit and receive important ingredients from existing organizational research and its view on organizational practices.

\section{B. Practice Research in Organizations}

We assume that a software development practice may become an organizational practice, which can be defined as the organization's routine use of knowledge. Organizational practices can exist at multiple levels, such as in a software development project or in an organization taking part in several projects or development processes (e.g., software development teams, groups, or companies). Organizational practices often have tacit components embedded partly in individual skills and partly in collaborative social arrangements [12], [17], [18].

Organizational practices have not been thoroughly studied and theorized in the software development context. The general management literature however theorizes with many viewpoints on how organizational practices take shape. For example, Szulanski [12] argues that a "best practice" represents organizational knowledge which can be transferred between a source and a recipient unit inside an organization as a replication of an organizational routine. Kostova and Roth [19] suggest that an organizational practice "evolves over time under the influence of the organization's history, people, interests, and actions" and that it comes "to reflect the shared knowledge of the organization and tend[s] to be accepted and approved by the organizational members". That is, a practice may be rationally adopted or may emerge in an evolutionary manner in an organization. Within the latter view, any identifiable practice can be phrased to be meaningful to the

Table 1: Most significant differences between the two modes of thinking [3, p. 56]

\begin{tabular}{|c|c|c|}
\hline & Technical rationality & Reflection-in-action \\
\hline Situations (Development contexts) & $\begin{array}{l}\text { Fall into scientifically defined } \\
\text { categories }\end{array}$ & $\begin{array}{c}\text { Are unique, complex, uncertain, and } \\
\text { value-conflictual. }\end{array}$ \\
\hline $\begin{array}{c}\text { Knowledge (of how to develop } \\
\text { software?) }\end{array}$ & $\begin{array}{l}\text { Is a result of science and must be } \\
\text { separated from practice }\end{array}$ & Is inseparable from action \\
\hline $\begin{array}{l}\text { Relationship between research and } \\
\text { practice }\end{array}$ & $\begin{array}{l}\text { Practice is fundamentally different } \\
\text { from research (science); practice is } \\
\text { application of theory and research is } \\
\text { production of theory }\end{array}$ & $\begin{array}{l}\text { Practice includes research and vice } \\
\text { versa }\end{array}$ \\
\hline
\end{tabular}


extent to which it is regarded as useful in a contextual, situated organizational activity [6].

Any existing description of a practice implies that at least one stakeholder in the organization has intended that it should be enacted. However, ethnographical studies have shown that such canonical, pre-described practices often deviate from the actual actions taken [20]. Moreover, software development organizations may follow undocumented practices. Pentland and Feldman [21] highlight a distinction between the performative and ostensive aspects of organizational routines. The performative aspect represents "the specific actions taken by specific people at specific times when they are engaged in what they think of as an organizational routine" (p. 796). The ostensive aspect is "the abstract or generalized pattern of the routine" (p. 796). The ostensive aspect is not necessarily a formal written description of the practice; it can also be the rationalized response given by a developer when asked how he or she is carrying out his or her work.

In summary, organizational research consider practices as organic and consequential to the organization itself [22]. Development and adoption of practices thus require reflection and understanding of their rationales and impacts, including the implicit ones. As Schulze \& Boland [8] note, there is often a difference between what people say they do, what they ought to do, and what they actually do. In addition, the reproductive aspects of practices, the effects of practices, what doing the practice does, including all its implicit effects, are often hidden from the participants and observers. An inquiry into organizational practices requires the reflection-in-action mode to knowledge. Our view is that studies that reflect and theorize software development practices in the real world context, in the field, can provide important knowledge for improving the practice. These kind of studies and theorizing should be situated to actual software development contexts, similarly as in the general practice research [23], and they should lead to reflective learning that can be generalized to theories. Following this line of thought we have developed a model for theorizing about software and systems development, which is presented in the following section.

\section{COAT HANGER MODEL FOR BUILDING THEORIES FROM PRACTICE}

Our framework builds on six main concepts which need to be distinguished in order to learn from development practice and to build theories of development practices: learning, $a$ practice, development context, rationale, impact, and theory. For each concept we use a dual naming, for example rationale/rationalizing and impact/evaluating (Figure 1). Practice theory [22], [24] sees situated actions as consequential in producing organizational structures. This means that actions themselves create and reproduce those organizational structures that they are constituents of. Therefore the double naming - the concepts are not only objects or entities in organizational structures but also actions or activities that reproduce the organization and themselves.

This section gives first a brief definition of these concepts separately, based on the previous literature. Secondly it ties them together as a framework through which theories of software development practices can be built by learning and reflecting from practice.

Lyytinen and Robey [25] relate learning, based on Argyris \& Schön [26], to the idea of "theories-in-use". To learn from practice requires that we identify or assume causal relationships between actions taken during the development and its desired outcomes [25]. Learning from a particular set of development actions requires that we treat development projects and actions as "experiments" from which we generate evidence to test selected theories-in-use with regard to selected ideas of development practices (ibid.).

A central concept in our framework is the concept of $a$ practice. One dictionary definition of a practice is "something people do regularly" [27]. In context of a development project or an organization, a systems development practice may become an organizational practice or routine, which can be defined as the organization's routine use of knowledge, especially "know-how" [17]. The concept of "best practices" illustrates an assumption that abstractions of such know-how can be usefully analyzed and lessons learned from practice can be transferred through them between organizational contexts and over time [e.g. 12]. However, organizational practices often have tacit components embedded partly in individual skills and partly in collaborative social arrangements [12], [17], [18]. If we compare a development method and a practice, a method adopted in an organization always embodies a predefined practice or a set of them, whereas a practice is not always defined at the detailed level, at least with regard to all potential elements [28] of method knowledge [16]. However, although being cautious on the concept of "best practices", we share the belief [29] that practice descriptions and definitions may appear as useful to analyze more or less recurrent development actions in context, as a basis of learning from them.

A software development effort takes place in a development context, which includes a large number of issues and factors [30]-[32]. For example, Clarke \& O’Connor [31] identify 140 situated factors that affect the software development process. Similarly in information systems development Orlikowski [32] identifies that the role of the system, systems development structure and operations, development policies and practices, development staff, corporate strategies, organizational structure and culture, customers, competitors, and available technologies represent contextual categories of issues which may influence changes in development practices.

Rossi et al. [33] discuss the concept of method rationale as an important part of evolutionary method engineering to support software and systems development. While they regard good understanding of method rationale as necessary for continuing "modification and augmentation" of an organization's methods, we will widen the concept of rationale to be as well useful for understanding reasons for an organization's development practices in general (i.e. also those practices in use, which do not necessarily fulfill the characteristics of a thorough method). A rationale for a development practice thus provides justifications for the 
creation, use and modification of the practice (or set of practices) of interest.

Lyytinen and Robey [25] emphasize the importance of learning from the organization's own development experience. If we adhere to the results of the first SEMAT GTSE workshop [2], this evidently requires analysis and identification of impacts of the development practices to software engineering success (including such dimensions as project schedule, cost, scope, software properties, time, market performance, and other success expectations held by the stakeholders). Such impacts may be desired already according to the explicit method rationale(s), or they may be unexpected, sometimes even unwanted.

Finally, these concepts are needed for creating and evaluating theories of development practices. That is, we pursue theories which can analyze, describe, and explain contextual software development practices, ultimately aiming at a level of prediction [34]. That is, we believe that it is useful to analyze the practice and aim at predictive theories of certain types of development practices, with regard to their impacts on the development products, projects and processes, and contexts.

In the following, let us relate these concepts to each other to form a framework to guide research on development practices. Figure 1 relates these concepts together whereas their relationships we need to understand in order to build theory from practices are discussed further below.

Learning is a boundary-spanning mechanism which need to exist, on the one hand, in a development context so that previous theories, including previous, more or less wellgrounded, methodological recommendations of development can inform local rationale for new practices and that observed impacts of the target organization's previous practices can inform further local rationality to adjust the practices. On the other hand, learning is needed between development organizations and the theory builders, who observe development actions (and local interpretations of such actions) in practice and try to abstract lessons to be learned from the particular practices in question (Figure 1).

Development context involves all the issues which have impact on how practices in the target organization or project are socially constructed and how the development organization can learn from its practices. The context has impact on rationale to implement new practices and how the implemented practices are twisted during actual development activities, on the impacts reached from the practices-in-use, and on the learning process and lessons learned. That is, practices, their impacts, and learning may not be purely based on the identified rationale alone, but can be affected by contextual issues (Figure 1). If contextual issues are explicitly identified before implementing a new set of practices, they become a part of the rationale. However, some contextual issues may have a more implicit effect on practices in use and their impacts, recognized only after new practices have been tried out.

Learning from local and contextual development practices requires good understanding of how practices are implemented and used in any target context of development. The contextual rationale(s) for particular practices and their improvements should cause meaningful change(s) in a practice or a set of practices, which are, again, often a part of the practice repertoire in the context. Moreover, contextual impact(s) after a practice has been introduced or changed need to be studied and lessons learned from the observed impacts need to be distilled (Figure 1).

If observed changes and improvements in local practices

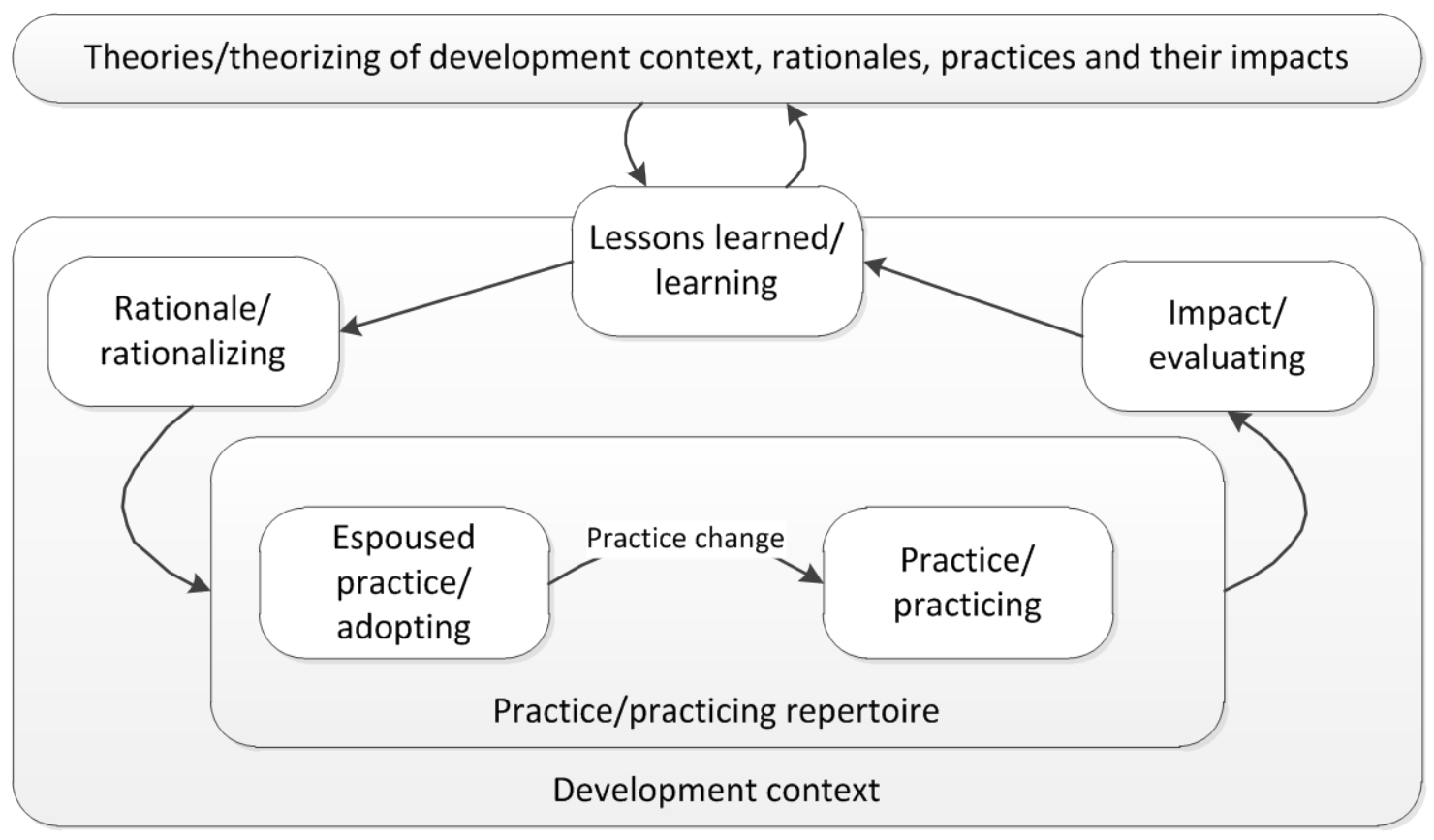

Figure 1. Coat Hanger model: a framework for building theories from development practices. 
are used to contribute to a theory of a selected set of generallevel development practices (beyond the context in question) through a learning process, then we need also to recognize ideas of more generic rationales giving reasons to implement certain types of practices, the very ideas and descriptions of those practices and their interrelation, and ideas of impacts realized from adhering to the practices in question. As well, generic ideas to categorize development contexts, which may have impact on rationales, enactment of particular practices, whether they are only espoused, but not really in use, and impacts resulting from particular practices, may be theorized. Through learning from the target context(s), development practice research may theorize further on more universal issues of the development context, their impact on rationales for practices, actual practice domains of interest, and the generalized ideas of impacts from choosing particular practices (Figure 1). Here, it is important to denote that the descriptions of development contexts, rationales, practices, and their impacts at the level of a theory should be distinguished from the observed practices (or local interpretations of practices) in the context and in use. This distinction has not been always very clear in the traditional studies of methods and their use as denoted e.g. by [29].

That is, we believe that theories of development practices should pursue to promote understanding of reasons why to consider implementation of particular idealized practices and impact of those practices, discussed in the light of theoretical categories of contextual issues and contingencies. Such theories would be able to answer to three research questions, which we believe to be of interest for scholars, educators, and practitioners:

- Why are particular (types of) practices followed (or not) in software development?

- What are the expected impacts (both desired and undesired) from adhering to a set of certain predescribed practices?

- How are certain types of development contexts expected to affect the rationale for, the impact on, and the implementation of certain pre-described practices?

\section{DISCUSSION}

The Coat Hanger model differs from the SEMAT kernel in many ways. In SEMAT the goal of theorizing seems to be the improvement of the practice by evaluating and selecting the best practices for the given context, whereas Coat Hanger aims at learning and reflection: it may, as a side product, improve the local practices through learning, but the goal is more at refining understanding and theories through learning from contextual experiences.

Ontologically SEMAT Essence [15] relies on seven predefined interconnected alphas and therefore its ontology is at least partly fixed and based on either previous experiences, conventional views or a best guess. Coat Hanger makes few, if any, specific assumptions on the ontology of professional software development practices. It assumes that there is a context and a rationale for changing or using the selected (and emerging) practices. It also assumes that the practices in use have impacts that can be evaluated and that the espoused practices, i.e. the pre-defined "official" practices for the intended way-of-working, are not always same as the actualized practices in use.

This ontological difference gives more freedom to theory creation. SEMAT has taken the standardization path where concepts are based on consensus and it seems to include the conception that theorizing resembles a one-time process: the theory about the central concepts and their relationships becomes "ready" when it is agreed by the authoritative parties involved. Instead of this one-time view we see theorizing as a continuous dialectic process between experience and theory. In the process both practice and theory evolve. We see no necessary end to this theorizing process. As contexts and practices change, so must theories follow or lead, depending on the status of the current research and practice. However, theorizing and suggested ontologies to theorize about software engineering may still be as such useful for researchers, educators, and even reflective practitioners.

We can also reflect the differences by using Schön's [10] distinction between two modes of thinking, technical rationality and reflection-in-action (see Section 2 above). In Nielsen [3], these two modes of thinking were summarized to have differences in situations, knowledge, and the relationship between research and practice. Technical rationality supposes that situations are known beforehand, whereas reflection-inaction sees situations as unique, complex, uncertain and valueconflictual. Technical rationality makes a distinction between knowledge and action, but reflection-in action regards knowledge as inseparable from action. From this follows that in technical rationality practice and research are qualitatively very different, i.e., the relationship is one-way: practice uses the results of research. The reflection-in-action mode makes a clear difference to this: practice is inseparable from research, theorizing needs contribution from the practice, and tasks in practice involve also research.

Table 2 uses the three differences defined by Nielsen [3] and illustrates how the SEMAT kernel and the Coat Hanger model differ in relation to the two modes of thinking. Our interpretation is that SEMAT (so far) represents largely the technical rationality when evaluated against these three points. In respect the situations, SEMAT seems to presuppose that there can be universal, situation-independent best practices that can be applied to clearly defined situations. It also seems to have the idea that knowledge can be extracted from the development context and refined to universal theories that would benefit to most contexts. Additionally, it makes a relatively clear distinction between research and practice and premises that research can produce universal solutions to software development practice. It also represents the thought that research is ultimately very different from practice.

In spite of this critique we see SEMAT as a legitimate initiative: it may direct the interests of researchers and practitioners to theories and theorizing in software development, which have been mostly missing from the discussion this far. Our critique is mostly targeted towards the concept of theories and theorizing, which, at least in light of the 
Table 2: SEMAT kernel and Coat Hanger in relation to two modes of knowledge

\begin{tabular}{|c|c|c|}
\hline & SEMAT kernel & Coat Hanger \\
\hline Situations (development contexts) & $\begin{array}{l}\text { In a development context, there is a } \\
\text { need for learning and adapting "best } \\
\text { practices" to the situation. } \\
\text { Alphas to describe the development } \\
\text { context and to "fit" the practices } \\
\text { and methods into it. } \\
\text { Technical rationality: ultimately the } \\
\text { use of defined categories - } \\
\text { situations and contexts can be } \\
\text { prescribed with the SEMAT alphas. }\end{array}$ & $\begin{array}{l}\text { The development context is unique } \\
\text { and complex with a multitude of } \\
\text { known and unknown factors } \\
\text { (cf.[31]). Although some pre- } \\
\text { defined practices may be adopted } \\
\text { and adjusted, the actual practice } \\
\text { also emerges due to contextual } \\
\text { factors - also in unpredictable ways. } \\
\text { Reflection-in-action: does not make } \\
\text { any presuppositions of the } \\
\text { significance of particular contextual } \\
\text { or situational factors }\end{array}$ \\
\hline $\begin{array}{c}\text { Knowledge (of how to develop } \\
\text { software) }\end{array}$ & $\begin{array}{l}\text { Mostly technical rationality: } \\
\text { knowledge comes primarily from } \\
\text { the previously defined practices of } \\
\text { software engineering. Some } \\
\text { practices can be planned locally, in } \\
\text { light of the SEMAT alphas. }\end{array}$ & $\begin{array}{l}\text { Reflection-in-action: knowledge is } \\
\text { dependent on the context and } \\
\text { grounded in learning from local } \\
\text { practices and their emerging } \\
\text { impacts or it may be learned from } \\
\text { applicable global or local theories. }\end{array}$ \\
\hline $\begin{array}{c}\text { Relationship between research and } \\
\text { practice }\end{array}$ & $\begin{array}{l}\text { Although SEMAT is "not for } \\
\text { methodologists", the aim is to help } \\
\text { practitioners to use and adapt } \\
\text { practices. This implies that the } \\
\text { practices have been developed } \\
\text { largely by someone else - and there } \\
\text { is thus a separation between those } \\
\text { who actually develop practices and } \\
\text { those who use them. } \\
\text { Technical rationality: researchers } \\
\text { produce the kernel and the theory } \\
\text { and practitioners apply the concepts } \\
\text { defined in them. }\end{array}$ & $\begin{array}{l}\text { Reflection-in-action: practitioners } \\
\text { learn, co-create, and reflect upon } \\
\text { local theories of contexts, } \\
\text { rationales, practices, impacts and } \\
\text { their dependencies. External } \\
\text { research may create important } \\
\text { theories and lessons to learn, trying } \\
\text { to reflect the contextual practices- } \\
\text { in-use against previously described, } \\
\text { abstract practices and documented } \\
\text { experiences from them. }\end{array}$ \\
\hline
\end{tabular}

organizational theories about work practices, seems a bit onesided. Theorizing about software engineering is a dialectic and continuous process, as the numerous contextual issues will always be in flux. In addition, much of software development research is more or less related to human action and human organizations. Therefore the reference sciences of software engineering research include not only computer science and mathematics but also organization sciences, psychology, management and sociology.

In light of this discussion and comparison, we can provide some suggestions for elaborating the SEMAT initiative:

- The Alphas \& Essence focus on describing intended practices to be adopted by the development organizations and projects. In this sense the approach is normative and presumes that practices can be designed and that they will be used as designed. It is, however, unclear how to observe their real fit when practices are to put in action to actual work, and whether they are used as prescribed. SEMAT should include a mechanism for reflection-in-action that evaluates the practices and adjusts according to the actual use of practices.

- To make theories of prediction and prescription concerning development practices more explicit, we suggest that three new alphas need to be included to the endeavor level of SEMAT. The alphas at the endeavor level should be added with the desired impacts, i.e. the rationale, and observed impacts to the software engineering success. In case learning from experiences by trying to use particular practices is desired, the aim to encapsulate lessons learned should also be added. In 
its current state, the SEMAT alphas do not provide support for "theorizing about practice" by practitioners or researchers. The three new suggested alphas would enable creating theories about software engineering success.

- In previous SEMAT examples [e.g. 34] the Work alpha has been slightly mixed with the planned "way of working". It needs to be clarified, whether the Work alpha will be used to describe the ACTUAL work whereas the "way of working" alpha will describe the INTENDED work practice? This remains unclear while new learning often happens when the actual work deviates from the planned, in case the reasons for that and impacts resulting from the deviation can be captured in the context of development. This also shows how research is integral to practice requiring reflection-in-action.

- The alphas describing the solution (requirements, software system), customer (opportunity, stakeholder), and endeavor (work, way of working, team) should be checked against the literature reviewing the contextual issues having impact on SE success [31].

While we presented our Coat Hanger model for theorizing of software engineering practices, our purpose was not to replace SEMAT but to show how integral learning from practice is to theorizing and that practices are often not used as intended. This way we hope that we can give a positive contribution to the development of SEMAT. We could also criticize Coat Hanger in light of SEMAT. For example, Coat Hanger could be elaborated further to include more explicit "alphas" concerning the software solution itself and the "customer". In this sense Coat Hanger is too general for providing direct support for the practice. However, we see the model more as a tool for researchers and educators to study the practice and to collaborate with (preferably reflective) practitioners.

\section{CONCLUSIONS}

Above, we explained the difference between technical rationality and reflection in action. Based on these concepts, we argued that the effort towards a general theory of software engineering would benefit from organizational practice theories. Upon this background, we sketched out the Coat Hanger model for theorizing of software engineering practices. The model is not presented as a normative statement of what such theories should include. Instead it reminds us of the important roles of learning and context in theorizing and illustrates explicitly that rationales or intentions do not always correspond to impacts and that practices in use are not always the same as those intended and initially adopted.

We also proposed some enhancements to the SEMAT essence. From our viewpoint SEMAT should make a clearer distinction between intended and actual practices. We thus suggest new alphas to describe rationale, deviations from intended practices, actual impacts, and lessons learned. In addition, SEMAT should stay reflective for future theoretical advancements, especially in organizational theory related to software development.

In the future we wish to continue our theory building on software development practices. When combined to our previous model on practice changes [16], the Coat Hanger model is expected to serve as a conceptually clear and useful instrument for theorizing. One alternative could be to build a catalogue of well-known or otherwise interesting software development practices, their rationales, and impacts on known contexts.

\section{REFERENCES}

[1] P. Johnson, M. Ekstedt, and I. Jacobson, "Where's the Theory for Software Engineering?," Software, IEEE, vol. 29, no. 5, pp. 96-96, 2012.

[2] P. Ralph, P. Johnson, and H. Jordan, "Report on the First SEMAT Workshop on General Theory of Software Engineering (GTSE 2012)," ACM SIGSOFT Software Engineering Notes, vol. 38, no. 2, 2013.

[3] P. A. Nielsen, "Approaches to Appreciate Information Systems Methodologies: A Soft Systems Survey," Scandinavian Journal of Information Systems, vol. 2, pp. 43-60, 1990.

[4] L. Mathiassen, "Reflective Systems Development, Volume 1," Aalborg University, 1998.

[5] M. Jackson, "Problems, Methods and Specialization," IEEE Software, vol. 11, no. 6, pp. 57-62, 1994.

[6] W. J. Orlikowski, "Knowing in Practice: Enacting a Collective Capability in Distributed Organizing," Organization Science, vol. 13, no. 3, pp. 249-273, May 2002.

[7] P. Bourdieu, "The Three Forms of Theoretical Knowledge," Social Science Information, vol. 12, no. 1, pp. 53-80, 1973.

[8] U. Schultze and R. Boland Jr., "Knowledge management technology and the reproduction of knowledge work practices," The Journal of Strategic Information Systems, vol. 9, no. 2-3, pp. 193-212, Sep. 2000.

[9] L. Mathiassen, "Systems Development and Systems Development Methods," University of Aarhus, Aarhus, Ph.D. Dissertation DAIMI PB-136, 1981.

[10] D. Schön, The Reflective Practitioner: How Professionals Think in Action. New York: Basic Books, 1983.

[11] P. R. Carlile, "A Pragmatic View of Knowledge and Boundaries: Boundary Objects in New Product Development," Organization Science, vol. 13, no. 4, pp. 442-455, 2002.

[12] G. Szulanski, "Exploring internal stickiness: Impediments to the transfer of best practice within the firm," Strategic Management Journal, vol. 17, no. Winter Special Issue, pp. 2743, 1996.

[13] N. Jørgensen, "The Engineering of Software: Views from Technology Theory," in Twenty-Sixth International Conference on Inofrmation Systems, Las Vegas, USA, 2005.

[14] S. Adolph, P. Kruchten, and W. Hall, "Reconciling perspectives: A grounded theory of how people manage the process of software development," Journal of Systems and Software, vol. 85, no. 6, pp. 1269-1286, 2012.

[15] SEMAT, "Essence - Kernel and Language for Software Engineering Methods (OMG ad/2012-11-01, Revised submission)," http://semat.org/wpcontent/uploads/2012/02/2012-11-01.pdf, 22-Jan-2013. 
[16] E. Å. Larsen, T. Päivärinta, and K. Smolander, "A model for analyzing changes in systems development practices," Journal of Information Technology Theory and Application, vol. 13, no. 3, 2012.

[17] B. Kogut and U. Zander, "Knowledge of the Firm, Combinative Capabilities, and the Replication of Technology," Organization Science, vol. 3, no. 3, pp. 383-397, Aug. 1992.

[18] R. R. Nelson and S. G. Winter, An Evolutionary Theory of Economic Change. Harvard University Press, 1982.

[19] T. Kostova and K. Roth, "Adoptionof an Organizational Practice by Subsidiaries of Multinational Corporations: Institutional and Relational Effects," Academy of Management Journal, vol. 45, no. 1, pp. 215-233, Feb. 2002.

[20] J. S. Brown and P. Duguid, "Organizational Learning and Communities-Of-Practice: Toward a Unified View of Working, Learning, and Innovating," Organization Science, vol. 2, no. 1, pp. 40-57, 1991.

[21] B. T. Pentland and M. S. Feldman, "Organizational routines as a unit of analysis," Industrial and Corporate Change, vol. 14, no. 5, pp. 793-815, Oct. 2005.

[22] M. S. Feldman and W. J. Orlikowski, "Theorizing Practice and Practicing Theory," Organization Science, vol. 22, no. 5, pp. 1240-1253, Oct. 2011.

[23] G. Goldkuhl and J. Lagsten, "The many prepositions of practice research: About, for, in, with and from," presented at the 2nd International Confrence on Practice Research, Helsinki, May 30-31 2012, 2012.

[24] P. Bourdieu, Outline of a Theory of Practice, vol. 16. Cambridge university press, 1977.

[25] K. Lyytinen and D. Robey, "Learning Failure in Information System Development," Information Systems Journal, vol. 9, no. 2, pp. 85-101, 1999.
[26] Argyris, Chris and Schön, D. A., Organizational Learning II. Reading, MA: Addison-Wesley, 1996.

[27] Collins CoBUILD, English Dictionary. 1989.

[28] J.-P. Tolvanen, "Incremental Method Engineering with Modeling Tools," University of Jyväskylä, Jyväskylä Studies in Computer Science, Economics and Statistics 47, 1998.

[29] B. Fitzgerald, N. L. Russo, and E. Stolterman, Information Systems Development: Methods in Action. Osborne/McGrawHill, 2001.

[30] L. McLeod and S. G. MacDonell, "Factors that affect software systems development project outcomes: A survey of research," ACM Comput. Surv., vol. 43, no. 4, pp. 1-56, 2011.

[31] P. Clarke and R. V. O'Connor, “The situational factors that affect the software development process: Towards a comprehensive reference framework," Information and Software Technology, vol. 54, no. 5, pp. 433-447, 2012.

[32] W. J. Orlikowski, "CASE Tools as Organizational Change: Investigating Incremental and Radical Changes in Systems Development," MIS Quarterly, vol. 17, no. 3, pp. 309-340, 1993.

[33] M. Rossi, B. Ramesh, K. Lyytinen, and J. P. Tolvanen, "Managing evolutionary method engineering by method rationale," Journal of the Association for Information Systems, vol. 5, no. 9, 2004.

[34] S. Gregor, "The nature of theory in information systems," MIS Quarterly, vol. 30, no. 3, pp. 611-642, 2006.

[35] M. Kajko-Mattsson, I. Jacobson, I. Spence, P. McMahon, B. Elvesater, A. J. Berre, M. Striewe, M. Goedicke, S. Huang, and M. MacIsaac, "Refounding software engineering: The Semat initiative (Invited presentation)," in Software Engineering (ICSE), 2012 34th International Conference on, 2012, pp. 1649-1650. 